\title{
DEVELOPMENT METHOD FOR REQUIREMENT COLLECTIVES OF HYDROGEN REFUELLING STATIONS
}

\author{
Schneider, David (1); \\ Huth, Tobias (1); \\ Nolte, Bastian (1); \\ Vietor, Thomas (1); \\ Heinke, Steffen (2); \\ Tegethoff, Wilhelm (2); \\ Köhler, Jürgen (2); \\ Kühne, Ulf (3); \\ Eilts, Peter (3); \\ Busche, Lisa (4) \\ 1: Technsiche Universität Braunschweig, Institute for Engineering Design; \\ 2: Technsiche Universität Braunschweig, Institut für Thermodynamik; \\ 3: Technsiche Universität Braunschweig, Institute of Internal Combustion Engines; \\ 4: TLK-Thermo GmbH, Braunschwei
}

\begin{abstract}
In addition to the development and research of battery-driven vehicles, a high research effort in the field of hydrogen technology can currently be observed. Various research and strategy initiatives relating to hydrogen are being initiated and pursued with considerable commitment worldwide. A significant expansion of the hydrogen filling station network is also being sought in Germany. In the course of designing a hydrogen refuelling station, the paradigms of thermal management must be taken into account in addition to a large number of different environmental and life phase-induced influencing factors. The interactions between influencing factors, requirements and the system architecture result in a multitude of possible refuelling station concepts, which can hardly be surveyed or managed from an organisational point of view. This publication introduces a method for the development of descriptive requirement collectives, which is applied to hydrogen refuelling stations in the framework of THEWA, but can also be adapted for other technical systems. The requirement collective is the first core element of the THEWA tool chain that enables a requirement-oriented and fast design of hydrogen refuelling stations.
\end{abstract}

Keywords: Requirements, Design methods, Conceptual design, Hydrogen refuelling station, Systems Engineering (SE)

\section{Contact:}

Schneider, David

Technische Universität Braunschweig

Institute for Engineering Design

Germany

da.schneider@tu-braunschweig.de

Cite this article: Schneider, D., Huth, T., Nolte, B., Vietor, T., Heinke, S., Tegethoff, W., Köhler, J., Kühne, U., Eilts, P., Busche, L. (2021) 'Development Method for Requirement Collectives of Hydrogen Refuelling Stations', in Proceedings of the International Conference on Engineering Design (ICED21), Gothenburg, Sweden, 16-20 August 2021. DOI:10.1017/pds.2021.123 


\section{INTRODUCTION}

With the objective to achieve national and global climate protection goals, the German states of Bremen, Hamburg, Mecklenburg-Western Pomerania, Schleswig-Holstein and Lower Saxony adopted a joint North German Hydrogen Strategy at the end of 2019. A core element of this strategy is the deployment of at least 250 hydrogen refuelling stations (HRS) in the five aforementioned northern German states. These HRS should be multimodal and thus suitable for various modes of transport such as road and rail vehicles or ships. (Ministries of Economy and Transport of the North German Coastal States, 2019) At present, about 16 public HRS are in operation in Northern Germany and 9 refuelling stations are in the planning or construction stage. However, all of them only allow for the refuelling of passenger cars and, moreover, can only cover a small number of daily refuelling operations due to their low capacity. (H2 Mobility Deutschland $\mathrm{GmbH}$, 2020) In order to achieve the climate goals and to implement the North German Hydrogen Strategy, it is therefore necessary to expand the North German HRS network with additional, more efficient refuelling stations designed for different modes of transport. An HRS can typically be divided into the four functional areas of hydrogen supply, storage, conditioning and delivery. (Stolten and Emonts, 2016) For each of these areas and the overall HRS system, there are different influencing factors and requirements, which lead to different possible technical solution concepts. As a central element, the thermal management of an HRS significantly influences the operability as well as energy efficiency and must be individually adapted to different refuelling station concepts. A great challenge for the development and conception of HRS systems result from the facts, that the advantageousness of a refuelling station concept is essentially determined by the type and number of the modes of transport to be refuelled (Reuß et al., 2017) and that the future direction of technological development in the fields of hydrogen and mobility cannot be estimated sufficiently.

\section{Objectives of this publication}

In order to enable a requirement-oriented and fast conception, design and simulation of hydrogen refuelling stations (HRS) the main objective of this publication is the introduction of a novel method for the development of a descriptive HRS model, further referred to as requirement collective. The requirement collective is as well as the analytical HRS model one of the core elements of a softwarebased tool chain that is being developed in the course of the project THEWA and aims to support the generation of suitable HRS concepts in dependence to different requirements. The uniqueness of this software-based tool chain is described in Chapter 2. Due to the high complexity of the whole tool chain and the limited extent of this publication, only the methodical elecitation of the requirement collective and its further use in the tool chain will be discussed in detail in this publication. In the course of this, Chapter 3 presents the method for developing a requirements collective as a whole, which essentially consists of 6 phases. The work contents and tasks of the individual phases are then described successively with reference also being made to the partial results achieved and the respective working progress in the project THEWA. In Chapter 4 this is followed by the integration of the requirements collective into the further work of THEWA - the creation of the software-based tool chain, whose objective is the enabling of a fast and requirement-oriented conception of HRS in dependence of different environment-induced influencing factors and requirements. Chapter 5 closes with a summary.

The contents presented in this publication were developed within the research measures of the project THEWA, which is characterised by close industrial collaboration with the companies Shell Oil Deutschland $\mathrm{GmbH}$, Maximator GmbH and MAN Truck \& Bus SE (MAN), as well as TLK-Thermo GmbH. The presented method for the development of requirement collectives was and is being applied on the creation of a descriptive HRS model and can furthermore be applied adaptively to other technical systems.

\section{FUNDAMENTALS AND CURRENT STATE OF RESEARCH}

After the commissioning, the first step in the development and conception of a product is the clarification of the technical task, whereby the project team collects all known product requirements depending on the product application and environment in a requirements collective. (Lindemann, 2016; Roth, 2001) To avoid faulty, outdated or incomplete requirement collectives, the disciplines of task clarification and requirements management are integrated under the term "Requirements 
Engineering" (RE). (Lindemann, 2016) In the course of the optimal conception of HRS, the most complete possible recording of all application-specific influencing factors and requirements poses great challenges for the developers. The complexity of the conception of an HRS is additionally increased by the fact that, depending on the existing requirements different technical solutions of the HRS core elements can be implemented, resulting in an almost unmanageable number of HRS concept variants, which address the local direct and indirect environment-induced influencing factors with varying degrees of effectiveness. The expansion of the HRS network is thus inhibited both in Northern Germany and globally by the fundamentally time-consuming and complex development of the most holistic requirement collectives possible and the resulting optimal conception of HRS.

\subsection{Software-aided development of requirement collectives}

There are widely established methods that can be used to develop requirement collectives. Some of the most popular methods are listed in Table 1.

Table 1. Established methods for requirement collective development

\begin{tabular}{|l|l|}
\hline \multicolumn{1}{|c|}{ Methods } & \multicolumn{1}{c|}{ References } \\
\hline Questionnaire / Customer survey & (Ehrlenspiel, 2009; Nehuis, 2014; Vajna, 2020) \\
\hline Benchmarking & $\begin{array}{l}\text { (Lindemann, 2016; Nehuis, 2014; Pahl et al., } \\
\text { 2007; Vajna, 2020) }\end{array}$ \\
\hline Quality function deployment & (Nehuis, 2014; Vajna, 2020) \\
\hline Checklists / Main feature list & (Lindemann, 2016; Pahl et al., 2007; Vajna, \\
& 2020) \\
\hline Conjoint analysis & (Akao, 2004; Saatweber, 2011; Vajna, 2020) \\
\hline
\end{tabular}

Although these purely methodical tools support the identification of relevant product requirements and their combination in a collective, they lack suitable mapping and structuring models with regard to the documentation of the requirements and the inherently existing interactions. (Nehuis, 2014) For this reason, in addition to the purely methodological tools, there are also information technology (IT) oriented approaches, which improve the identification, documentation and general handling of the increasingly complex product requirements. While the optimisation of content is a main focus of the methodological tools, the aim of IT-based tools is to increase effectiveness, for example by automating repetitive activities. (Ahrens) The discipline of Model-based System Engineering (MBSE) is a core element of software-supported documentation and modelling of requirement collectives and is based on the paradigms of System Engineering (SE). SE is understood as a meta-discipline that links the information flows of different disciplines (software, electronic, mechanical development among others) by providing suitable interfaces and processes and thus enables the efficient handling of technically high system complexities. (Huth and Vietor, 2020; Weilkiens et al., 2016) MBSE adopts the basic principles of SE, but bypasses the shortcomings of a purely document-based approach of documentation, thus enabling (digital) model-based documentation and especially modelling of environment-induced influencing factors and requirements of a product.

\subsection{Software-aided methods for the conceptual development of hydrogen refuelling stations}

Technical systems can be modelled descriptively and analytically. Descriptive models, such as requirement collectives, describe a system and its environment on a functional level. They can take several perspectives, such as a black box and white box perspective (see Chapter 3.1). Analytical models, on the other hand, as applied in the course of computer-aided design of HRS, operate on the level of system architecture and describe interactions between individual system components. The integration of descriptive and analytical HRS models enables the development of a software-based tool chain that simplifies the conception of HRS. Thereby, influencing factors and resulting requirements are linked to the system architecture of different HRS concepts and serve as indicators for the development of the optimal HRS with regard to the direct and indirect environment-induced conditions. Despite the great potential added value, currently is no research being done on the development of such a software-based tool chain. Although, the basic tools for the analytical modelling and simulation of HRS systems are available for the most part, there is currently no tool that enables a flexible combination of different subsystems and elements of an HRS and can map different 
overall system topologies (concept variants). The relevance of such a tool chain is underlined by current national and international research efforts. For example, within the framework of the $H 2 B Z$ initiative of the Federal State of Hesse (Germany), approaches for the planning and design of HRS have been developed and summarised in the form of a guideline, which in the course of its application, however, makes use of targeted questions, but is not founded on MBSE-based modelling. (HA Hessen Agentur GmbH, 2012) Within the framework of the published study of the U.S. Department of Energy, the long-term implementation of a hydrogen-based transport economy is considered on the level of the System of Systems, from which the potential of MBSE-based complexity management of HRS is evident but not exploited. (Duffy and Sandor, 2008)

In summary, it can be stated that there is a lack of studies, analyses as well as solution concepts for a holistic treatment and conception of HRS systems under consideration of the individual requirements, expectations and boundary conditions. The project "THEWA - Thermal Management of Hydrogen Refuelling Stations", funded by the Ministry of Science and Culture (MWK) of Lower Saxony (Germany), is dedicated to the development of a tool chain that integrates descriptive and analytical HRS models and supports the conceptual development of HRS as well as the expansion of the national and international HRS network. In the course of THEWA a unique method for the development of a HRS requirement collective that can be adopted to any other technical systems has been developed and will be introduced in the following sections of this publication.

\section{ADAPTIVE METHOD FOR DEVELOPING A REQUIREMENTS COLLECTIVE FOR A TECHNICAL SYSTEM}

In the course of developing a generic requirements collective for HRS, the method shown in Figure 1 is currently being applied within the framework of the project THEWA. It was developed at the beginning of the project for the purpose of a strategic and effective objective pursuit. It is essentially characterised by 6 phases and can be applied adaptively for the creation of environment-induced requirement collectives of other technical systems. In Figure 1 the 6 phases and their subordinate elements and measures (grey boxes) are shown.

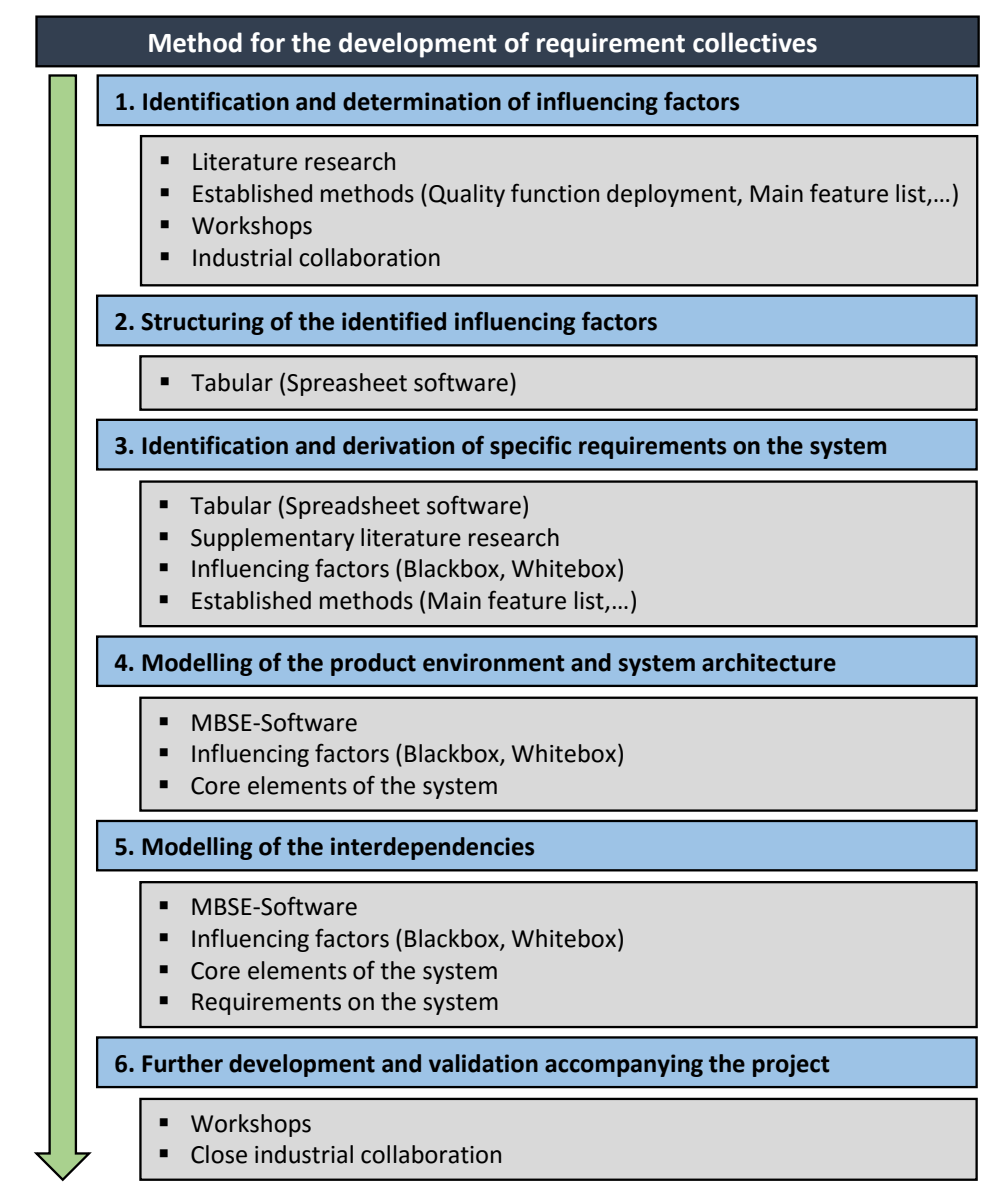

Figure 1. Method and subordinate elements for the development of requirement collectives 


\subsection{Phase 1 - Identification and determination of influencing factors}

The method for developing a requirements collective for a technical system is initiated by identifying influencing factors. This is done on the basis of established methods, which are applied in the context of the task clarification of requirement engineering (see Table 1), systematic literature research and workshops with research and industry partners.

In the project THEWA, systematic literature research was carried out for the purpose of identifying direct and indirect influencing factors of a HRS and established methods of task clarification such as the main feature list were applied. In order to identify further influencing factors of an HRS, in the field of research on mobility, a workshop was held with scientific staff from the projects "Zukunftslabor Mobilität" and "autoMoVe" of the Automotive Research Centre Niedersachsen (NFF) of the Technische Universität Braunschweig, which focus on the development of future scenarios of mobility and the elecitation of requirement collections for innovative vehicles. Based on these measures, a meta-model of a generic HRS environment was developed (Figure 2) in order to clarify and visualize possible lifecycle- and environment-induced influencing factors of an HRS and their inherent interdependencies. In the course of this, the observation was made, that the lifecycle- and environment induced influencing factors can be allocated to the HRS on a superordinate level or to specific HRS elements on a detailed level of perspective. Thus, the approach of differentiation between an HRS black box perspective and an HRS white box perspective was developed and applied.

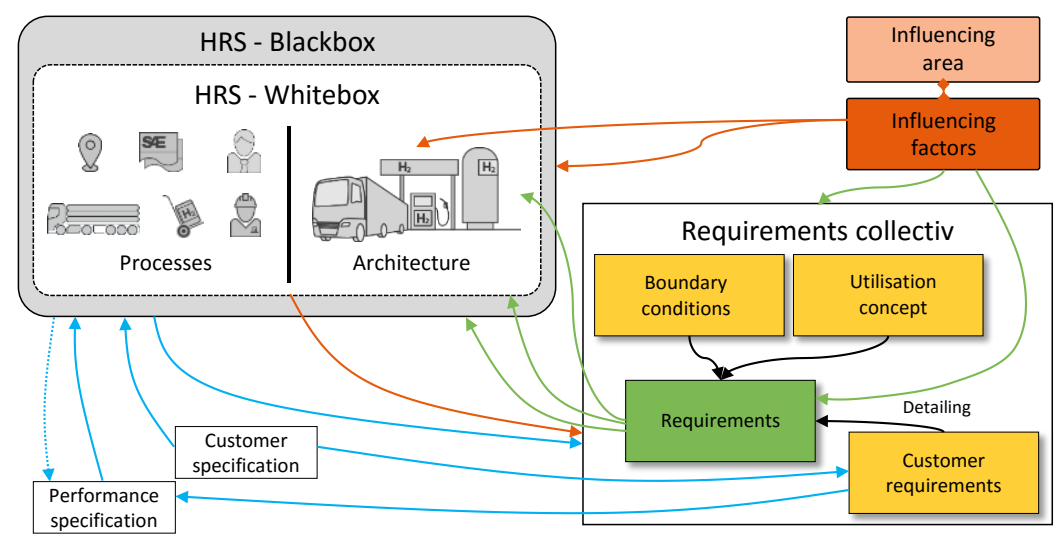

Figure 2. Metamodel of an HRS environment

In summary, 87 influencing factors have been identified with regard to the black box perspective and 93 influencing factors have been identified with regard to the specific elements of the white box perspective on an HRS.

\subsection{Phase 2 - Structuring of the identified influencing factors}

After the initial identification of influencing factors to be included in the conceptual design of an HRS, their systematic documentation and tabular structuring are performed in Phase 2. A spreadsheet software was used for this purpose in THEWA. The 87 influencing factors of the HRS black box perspective were structured into 5 main categories of environment, society, infrastructure, legislation and regulations as well as market and further 19 sub-categories. The 93 identified influencing factors of the white box perspective were subdivided into the 5 main categories of planning, development, production, use as well as dismantling/recycling and 17 additional subcategories. Phase 3 Identification and derivation of specific requirements on the system.

From the tabular documentation of the influencing factors, requirements on the technical system are derived in Phase 3, which have to be considered in the course of the conceptual design of the system. This derivation is based on the interaction between influencing factors, requirements and a system architecture as shown in Figure 3. Thus, from the environment-induced influencing factors different system requirements can be derived, which in turn define the characteristics and properties of a system and its components. For example, from the usage-induced influencing factor "Distance of an HRS to the hydrogen supplier", the following requirement for the hydrogen supply of an HRS can be derived: "Realise minimum transport costs and times through suitable site location". The initial collection of requirements resulting from Phase $\mathbf{3}$ can be supplemented based on further literature research, industrial workshops or the application of established methods of task clarification. In the project 
THEWA 182 requirements were derived from the 180 influencing factors in a first attempt. The structuring of the requirements was based on the main feature list according to Feldhusen (2013), which is divided into the areas of concept, lifecycle and organisation.

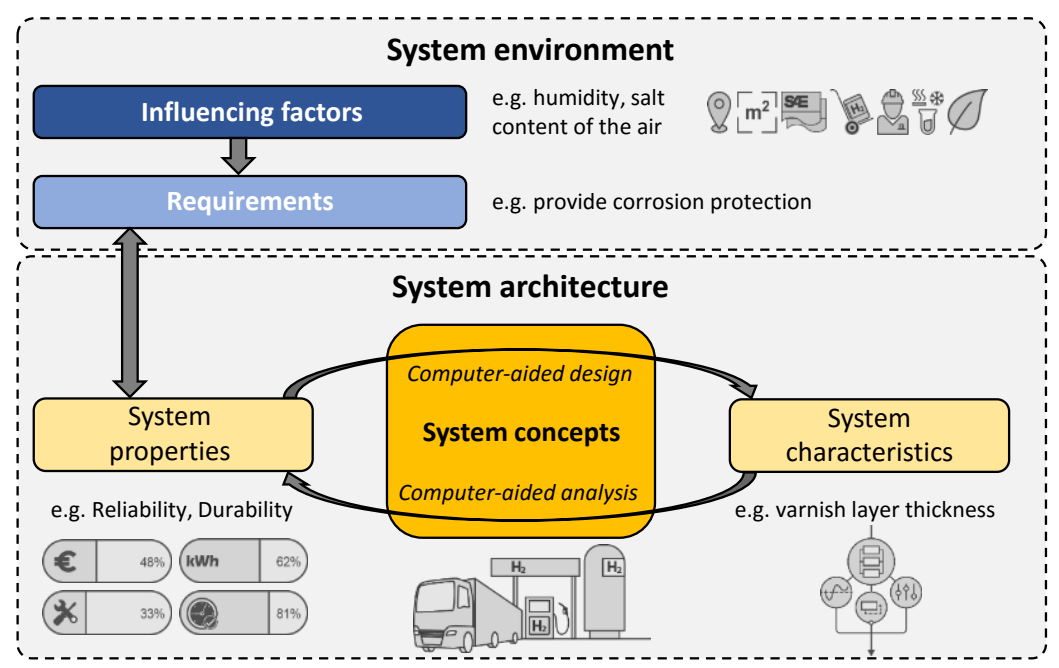

Figure 3. Interactions between influencing factors, requirements and system architecture, based on (Prinz et al., 2013)

\subsection{Phase 4 - Modelling of the product environment and system architecture}

In order to enable the final requirements collective to be applied in the early phases of system conception or industrial customer projects, Phase 4 includes the software-based modelling of the product environment. This is done on the basis of the paradigms of MBSE (Chapter 2). In the course of the modelling, the results of Phase $\mathbf{1}$ to Phase $\mathbf{3}$ and thus the influencing factors, the requirements and their structuring are modelled software-based.

In the project THEWA, MBSE-based modelling was carried out using the software Enterprise Architect (EA) from SparxSystems. As an example, the influencing factor "Distance of an HRS to the hydrogen supplier", mentioned in Section 4.3 was mapped to the subcategory of "Hydrogen Supply" and the superordinate category of the HRS white box. As another example Figure 4 shows the modelling of the influencing factors of the sub-category climate elements as part of the superordinate category of the HRS black box.
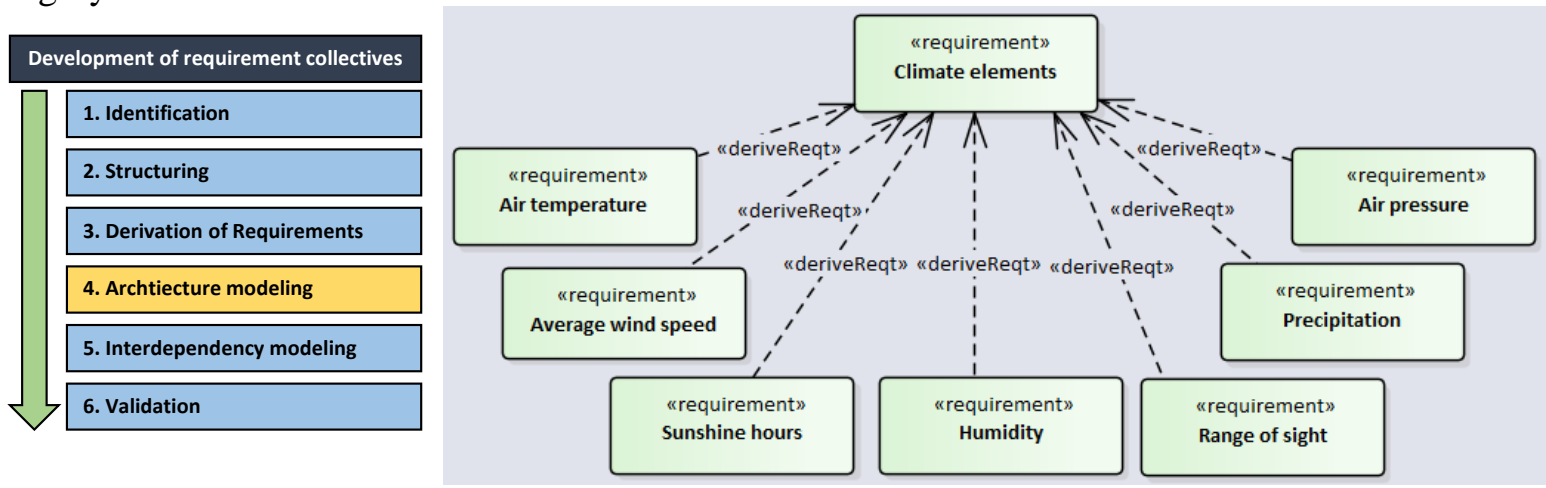

Figure 4. Schematic presentation of software-aided modelling of influencing factors

Besides the product environment, MBSE-based modelling is also used to model the system architecture, whereby the modelling procedure is similar. In preparation for Phase $\mathbf{5}$ - the modelling of interdependencies - the system architecture of an HRS was also modelled in THEWA, although the system was initially only described on a rough functional level. Since the final set of requirements is to be further refined in cooperation with industry, the overall description of the main components of an state-of-the-art HRS was initially sufficient. The project-internal understanding of an HRS, which is shown in Figure 5, was used as a basis. 

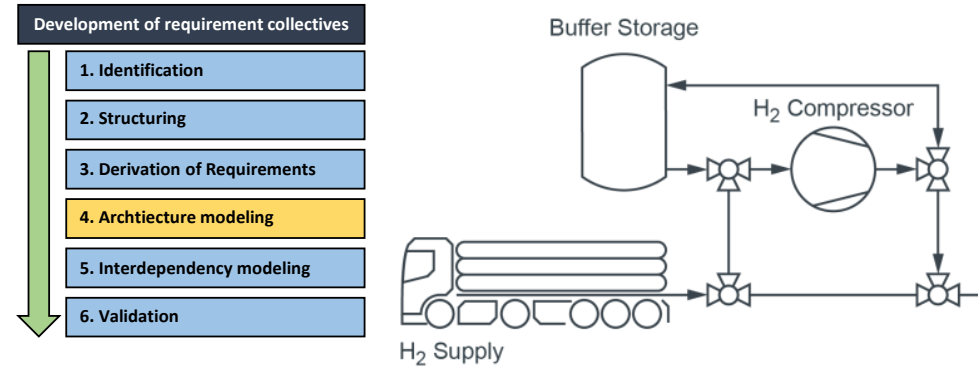

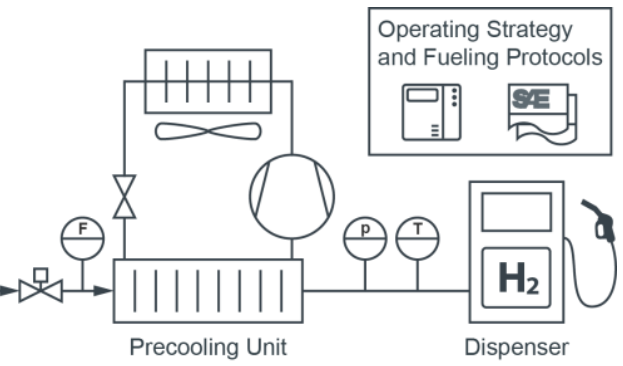

Figure 5. Main components of a hydrogen refuelling station (HRS)

\subsection{Phase 5 - Modelling of the interdependencies}

The modelling of interdependencies describes the MBSE-based documentation of interactions and correlations between influencing factors, requirements and the basic system architecture and is reserved for Phase $\mathbf{5}$ of the method for the development of a requirements collective. This modelling forms the basis of the association support in the conception of a product in the context of product development or customer projects, as it enables the rapid identification and retrieval of relevant environment-induced influencing factors and requirements for each system element and visualises important correlations through networks. The conception of a system can thus be carried out with a high degree of certainty in the consideration of relevant requirements and influencing factors. For example, by identifying an interaction between the climatic element "humidity" and the HRS core element "pipes", the requirement of "ensuring a certain reliability through suitable corrosion protection" can be derived.

The modelling of the interdependencies between influencing factors, requirements and system architecture is currently being carried out in the project THEWA and will continue due to the high number of model elements. To make the modelling easier to understand, Figure 6 shows a section of the interdependencies between the influencing factors of the sub-category climate elements and the main components of an HRS. The modelling of the interdependencies is performed in the same way as the modelling of the product environment and system architecture with EA.
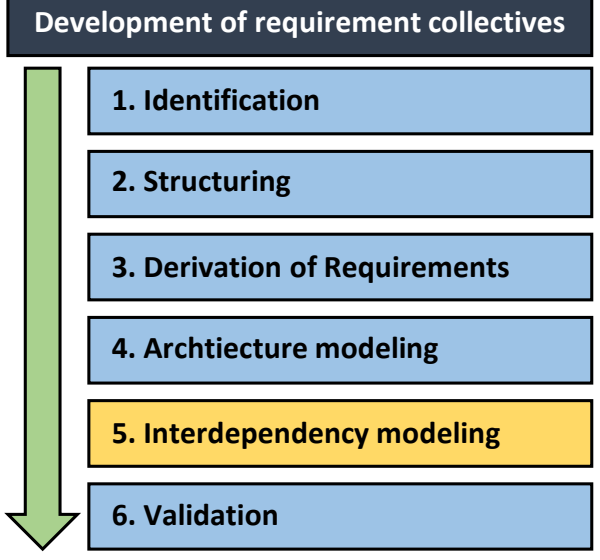

\begin{tabular}{|c|c|c|c|c|c|c|c|}
\hline Core elements & $\begin{array}{l}\text { ते } \\
\stackrel{0}{7} \\
0 \\
\text { d } \\
\text { I }\end{array}$ & 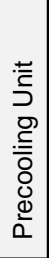 & $\frac{\frac{0}{0}}{\text { क }}$ & $\begin{array}{l}\mathscr{ఖ} \\
\stackrel{0}{2}\end{array}$ & 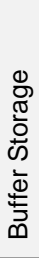 & 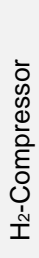 & 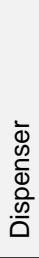 \\
\hline Average wind velocity & & & & & & & $X$ \\
\hline Air pressure & $X$ & $\mathrm{X}$ & & $X$ & 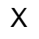 & $\mathrm{X}$ & $X$ \\
\hline Humidity & $X$ & $X$ & & $\mathrm{X}$ & $\mathrm{X}$ & $\mathrm{X}$ & $\mathrm{X}$ \\
\hline Air temperature & $X$ & $X$ & $\mathrm{X}$ & $X$ & $\mathrm{X}$ & $\mathrm{X}$ & $\mathrm{X}$ \\
\hline Percipitation & $X$ & & $X$ & $X$ & & & $\mathrm{X}$ \\
\hline Range of sight & $X$ & & & & & & $X$ \\
\hline Sunshine hours & & $X$ & $X$ & & $X$ & $X$ & $X$ \\
\hline
\end{tabular}

Figure 6. Interdependencies between influencing factors with regard to climate elements and core elements of a hydrogen refuelling station

\subsection{Further development and validation accompanying the project}

With the conclusion of phase 5 and the associated completion of the initial requirements collective, in Phase 6 this is followed by the detailing and further development of the collective with regard to the influencing factors used, requirements resulting and the system architecture considered.

In the project THEWA, following the creation of the initial and MBSE-based HRS requirements collective, the increased involvement of the industrial partners mentioned in Chapter $\mathbf{2}$ is intended for the further development and validation of the collective. In this process, the influencing factors as well 
as the requirements will be further specified based on the expert knowledge of the industrial partners and linked with the system architecture on a detailed level. Furthermore, in the course of the further development of the model, future scenarios will be increasingly developed and linked with several HRS concepts.

\subsection{Current development progress of the requirement collective in THEWA}

Figure 7 shows the current status of the development of the initial requirement collective of an HRS. The survey of the influencing factors as well as their documentation and structuring has already been carried out. The identification and derivation of the requirements for HRS, based on the influencing factors and further research, has also been carried out. Currently, the modelling of the HRS environment is taking place, whereby the influencing factors and requirements collected so far are documented on the basis of the paradigms of MBSE. Also the modelling of the interactions and interdependencies between influencing factors, requirements as well as main functional elements of an HRS is currently in progress. Only Phase 6, the validation and further development of the initial requirements collective, is still pending. In its course, the requirement collective will be specified, whereby the HRS system architecture will be detailed and the influencing factors as well as requirements will be validated for essential, conceptual relevance.

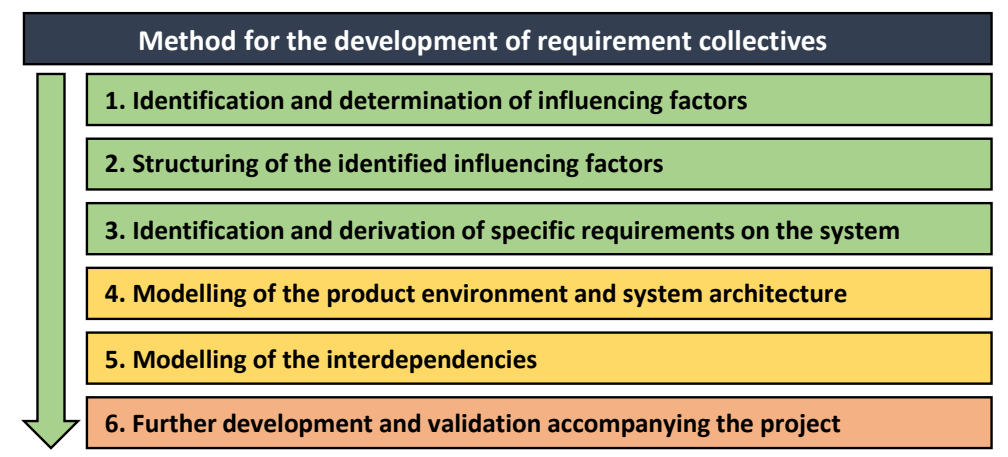

Figure 7. Current development progress of the requirement collective in THEWA

\section{INTEGRATION OF THE REQUIREMENT COLLECTIVE IN THE DEVELOPMENT OF A SOFTWARE-BASED TOOL CHAIN}

Simultaneously to the development of descriptive HRS modelling in the form of a generic requirements collective, analytical models of various HRS concepts are developed and modelled in THEWA. Descriptive and analytical modelling will be merged with the objective of providing an integrated tool chain, which can be used in the early phases of product development, in order to support the fast and requirement-oriented conception of HRS. Thus, in the sense of a design catalogue (Roth, 2001) or a morphological box (Pahl et al., 2007; Vajna, 2020), an optimal refuelling station concept should be recommended for different environmental conditions, motivations and initial situations. The catalogue is schematically shown in Figure 8.

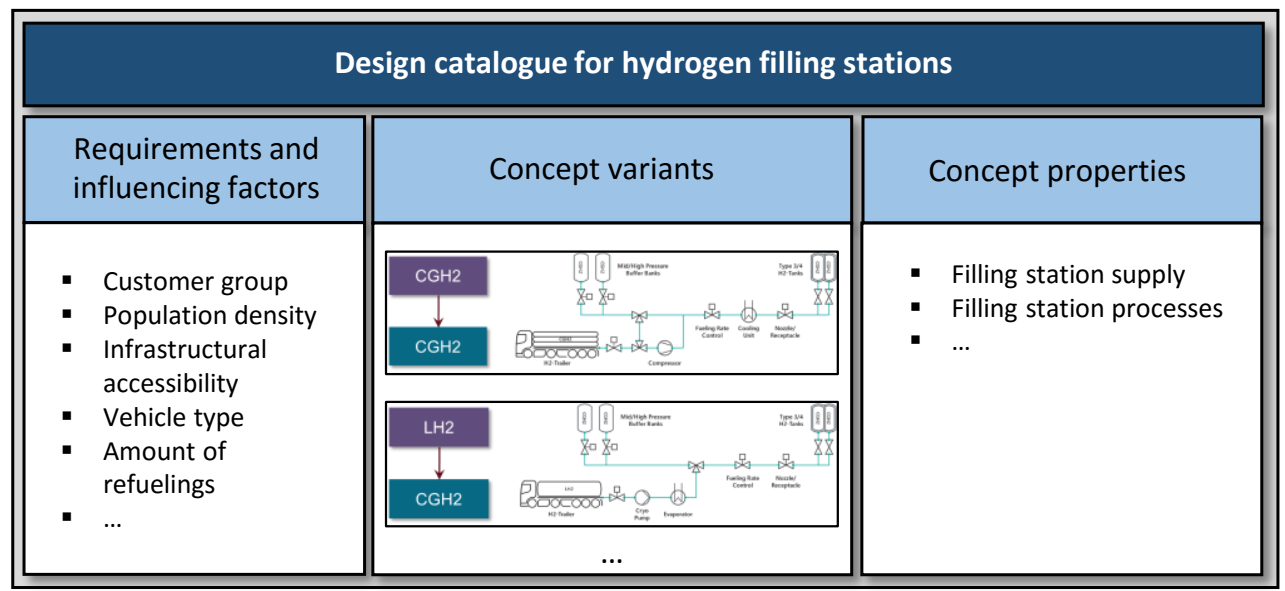

Figure 8. Schematic illustration of the HRS design catalogue structure 
In the left-hand column, relevant requirements as well as influencing factors and their characteristics are listed - for example, the customer group and population density. According to the listed requirements and influencing factors, different HRS concepts are suggested in the middle column as a solution variant, similar to a design catalogue. In the right column of the HRS design catalogue, the corresponding concept properties, such as the number of specific refuelling station elements or the properties of fuel storage and supply on an analytical and quantitative level, are recorded.

The basis of the HRS design catalogue, shown in Figure 8, is the combination of descriptive and analytical modelling. The descriptive modelling of the HRS includes the requirements collective described in Chapter 3 and the inherent interdependencies of requirements, influencing factors and system architecture. The analytical modelling of the refuelling station represents a library of technically feasible solution approaches and includes various HRS concepts as well as their behavioural simulations (see Figure 2). Figure 9 shows which elements and information of the design catalogue (Figure 8) can be traced back to the contents of the descriptive or analytical HRS model.

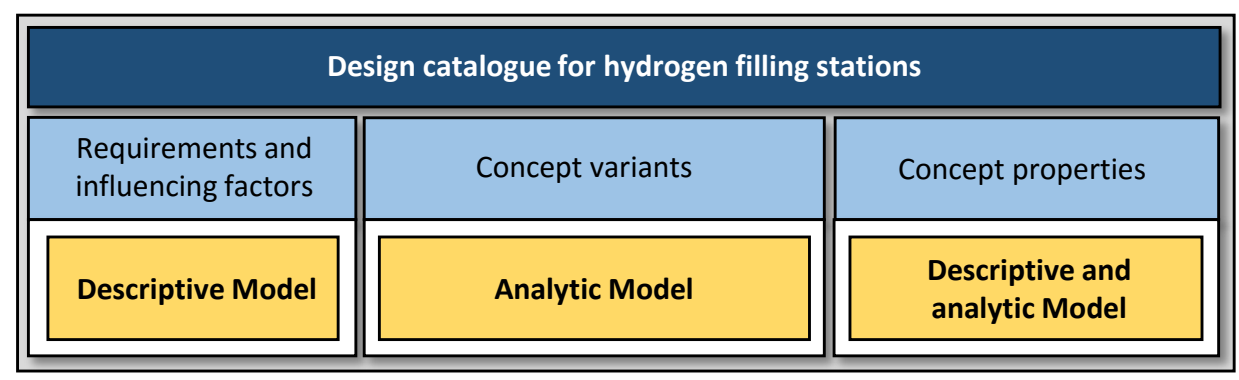

Figure 9. Assignment of descriptive and analytic modelling to the design catalogue contents

The analytical description and modelling of the refuelling station concepts is based on systematic literature research, project-based future scenarios developed with reference to mobility and industrial interviews as well as workshops with the project partners SHELL, MAXIMATOR, TLK and MAN. The interface between the descriptive and analytical modelling is provided by the advantages and disadvantages of the different refuelling station concepts, the expectations of the developers regarding the refuelling station characteristics as well as basic design rules and guidelines.

\section{CONCLUSION AND OUTLOOK ON FURTHER RESEARCH}

The central subject of this publication is the presentation of a unique method for the development of requirement collectives for technical systems on the basis of descriptive modelling, which is currently applied in the course of the development of a software-based tool chain to support the design of hydrogen refuelling stations (HRS) in the research project THEWA. In relation to the current state of research in the field of requirement engineering, the method is novel and essentially consists of 6 phases, which are described in more detail in this publication. In each case, a reference is made to the application of the method or the implementation of the respective phase in the THEWA project. Phase 1 of the method consists of the identification of environmental and use-induced influencing factors that affect the system under investigation, which in this publication is an HRS. In phase 2, the influencing factors are then structured in tabular form and assigned to suitable categories. This is followed by the identification and derivation of requirements for the system on the basis of the influencing factors recorded. Phase 4 and phase 5 of the method include the modelling of the product environment as well as the product architecture and the inherent interdependencies of the captured elements. Phase 6 concludes the method for the development of requirements collectives and includes the further development and validation of the collective created during the phases 1-5.

The introduced method represents an important partial result of the research efforts in the THEWA project, as the developed requirements collective is used in the course of a software-based tool chain for the support of a fast and requirements-oriented design and conception of hydrogen refuelling stations. This involves linking descriptive and analytical refuelling station models, which is also discussed in more detail in this publication. The further research in the THEWA project includes the revision and refinement of the created requirements collective in cooperation with the industry, whereby the recorded requirements and influencing variables as well as their interdependencies are 
checked for relevance, reasonability and comprehensibility. The industrial partners have a high level of expertise in the field of mobility and are therefore well suited for the further development of the requirements collective. Further research measures will also consist of further developing and practically implementing the approach presented in this publication for the creation of a softwarebased design and conception tool. The overall objective of THEWA and this publication is to accelerate the expansion of the national and international HRS network. A final outcome of the project will be a design catalogue, that contains and integrates descriptive and analytical information on different HRS concepts that address different requirements and thus enables a fast as well as requirement-oriented conception of HRS.

\section{ACKNOWLEDGMENTS}

This paper was developed in the course of the project "THEWA" (Thermal Management of Hydrogen Refuelling Stations), which is funded by the funding initiative "Niedersächsisches Vorab" and the Ministry of Science and Culture (MWK) of Lower Saxony (Germany). THEWA is industrial supported by the companies Shell Oil Deutschland GmbH, Maximator GmbH and MAN Truck \& Bus SE (MAN), as well as TLK-Thermo GmbH.

\section{REFERENCES}

Ahrens, G. Das Erfassen und Handhaben von Produktanforderungen [Online], Technische Universität Berlin, Fakultät V - Verkehrs- und Maschinensysteme. Available at https://depositonce.tu-berlin.de/handle/11303/ 435 (Accessed 8 March 2021).

Akao, Y. (2004) Quality function deployment: Integrating customer requirements into product design, Cambridge, Mass., Productivity Press.

Duffy, M. and Sandor, D. (2008) '4.4.1 A System-of-Systems Framework for the Future Hydrogen-Based Transportation Economy', INCOSE International Symposium, vol. 18, no. 1, pp. 507-521.

Ehrlenspiel, K. (2009) Integrierte Produktentwicklung: Denkabläufe, Methodeneinsatz, Zusammenarbeit, 4th edn, München, Wien, Hanser.

H2 Mobility Deutschland GmbH (2020) H2 live [Online]. Available at https://h2.live/en.

HA Hessen Agentur GmbH (2012) Wasserstoff-Tankstellen - Ein Leitfaden für Anwender und Entscheider, 3rd edn, Kassel.

Huth, T. and Vietor, T. (2020) 'Systems Engineering in der Produktentwicklung: Verständnis, Theorie und Praxis aus ingenieurswissenschaftlicher Sicht', Gruppe. Interaktion. Organisation. Zeitschrift für Angewandte Organisationspsychologie (GIO), vol. 51, no. 1, pp. 125-130.

Lindemann, U. (2016) Handbuch Produktentwicklung, München, Hanser.

Ministries of Economy and Transport of the North German Coastal States (2019) Hydrogen strategy for north germany [Online]. Available at https://www.hamburg.de/contentblob/13874168/ e484c76e44486905abd9220bbdd64a8f/data/hydrogen-strategy-for-north-germany.pdf.

Nehuis, F. (2014) Methodische Unterstützung bei der Ermittlung von Anforderungen in der Produktentwicklung, München, Verl. Dr. Hut.

Pahl, G., Beitz, W., Feldhusen, J. and Grote, K.-H. (2007) Engineering Design, London, Springer London.

Prinz, A., Nehuis, F., Vietor, T. and Stechert, C. (2013) 'The Effects of Regional Specific Requirements on the Development of Vehicle Concepts', in Lienkamp, M. (ed) Conference on Future Automotive Technology, Wiesbaden, Springer Fachmedien Wiesbaden, pp. 167-190.

Reuß, M., Grube, T., Robinius, M., Preuster, P., Wasserscheid, P. and Stolten, D. (2017) 'Seasonal storage and alternative carriers: A flexible hydrogen supply chain model', Applied Energy, vol. 200, pp. 290-302.

Roth, K. (2001) Konstruieren mit Konstruktionskatalogen, Berlin, Heidelberg, Springer Berlin Heidelberg.

Saatweber, J. (2011) Kundenorientierung durch Quality Function Deployment: Produkte und Dienstleistungen mit QFD systematisch entwickeln, 3rd edn, Düsseldorf, Symposion.

Stolten, D. and Emonts, B. (2016) Hydrogen Science and Engineering, Berlin, Wiley-VCH Verlag GmbH.

Vajna, S., ed. (2020) Integrated Design Engineering, Cham, Springer International Publishing.

Weilkiens, T., Lamm, J. G., Roth, S. and Walker, M. (2016) Model-based system architecture, Hoboken, New Jersey, Wiley. 